\title{
Lightning accidents in Nigeria: with special attention to aviation mishaps
}

\begin{abstract}
Lightning related accidents in Nigeria, a country of high lightning density, have been collected and analyzed. Results show that lightning related human injuries and deaths are very high in Nigeria, where the actual figure may reach as high as 500 deaths per year. However, due to the social stigma attached to lightning incidents and the lack of unbroken news chains reaching media, collection of accurate statistics has become a daunting task. Apart from human and livestock related hazards; property damage is also of high concern due to probable devastating consequences of such incidents. Extra attention has been paid on collecting damage records related to aviation industry as there are several serious accidents related to lightning have been reported in this area. The data collected and analysed is used to develop a set of national level recommendations for lighting safety and protection which can also be applicable in neighbouring countries, as they also experience extremely high lightning occurrence density.
\end{abstract}

Keyword: Lightning; Aero planes; Nigeria; Step potential; Direct strikes; Aviation accidents 